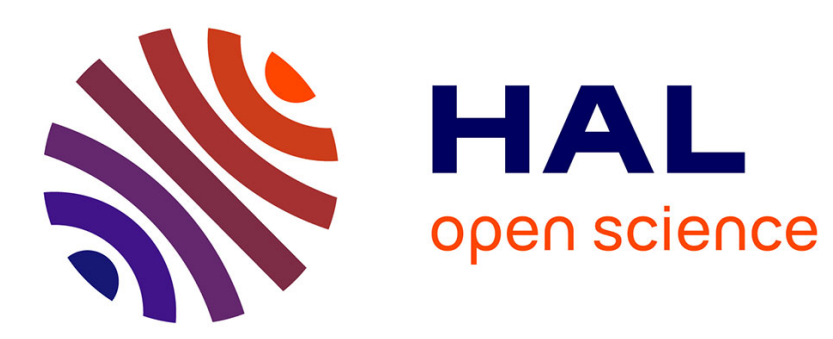

\title{
Implementation of specific motor expertise during a mental rotation task of hands
}

Hamdi Habacha, Corinne Molinaro, Montassar Tabben, Laure Lejeune

\section{To cite this version:}

Hamdi Habacha, Corinne Molinaro, Montassar Tabben, Laure Lejeune. Implementation of specific motor expertise during a mental rotation task of hands. Experimental Brain Research, 2014, 232 (11), pp.3465-3473. 10.1007/s00221-014-4029-3 . hal-02266679

\section{HAL Id: hal-02266679 \\ https://hal.science/hal-02266679}

Submitted on 19 Jun 2021

HAL is a multi-disciplinary open access archive for the deposit and dissemination of scientific research documents, whether they are published or not. The documents may come from teaching and research institutions in France or abroad, or from public or private research centers.
L'archive ouverte pluridisciplinaire HAL, est destinée au dépôt et à la diffusion de documents scientifiques de niveau recherche, publiés ou non, émanant des établissements d'enseignement et de recherche français ou étrangers, des laboratoires publics ou privés. 
Implementation of specific motor expertise during a mental rotation task of hands Hamdi Habacha $^{\mathrm{a}}$, Corinne Molinaro ${ }^{\mathrm{a}}$, Montassar Tabben ${ }^{\mathrm{b}}$, and Laure Lejeune-Poutrain ${ }^{\mathrm{a}}$ Université de Caen Basse-Normandie, EA 4260, F-14032 Caen, France

$$
\text { Author's Note }
$$

a Normandie Université, France, UNICAEN, CesamS, F-14032 Caen, France. Phone number:

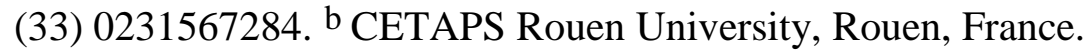

Corresponding author: Hamdi Habacha, E-mail address: hamdi.habacha@gmail.com 


\section{Abstract}

Mental rotation of the hands classically induces kinesthetic effects according to the direction of the rotation, with faster response times to the hands' medial rotations compared with lateral rotations, and is thus commonly used to induce engagement in motor imagery (MI). In the present study, we compared performances of table tennis players (experts on hand movements), who commonly execute and observe fast hand movements, to those of soccer players (non-experts on hand movements) on a mental rotation task of hands. Our results showed a significant effect of the direction of rotation (DOR) confirming the engagement of the participants in MI. In addition, only hand movement experts were faster when the task figures corresponded to their dominant hand compared with the non-dominant hand, revealing a selective effect of motor expertise. Interestingly, the effect of the DOR collapsed in hand movement experts only when the task figures corresponded to their dominant hand, but it is noteworthy that lateral and medial rotations of the right hand stimuli were not faster than medial rotations of the left hand stimuli. These results are discussed in relation to possible strategies during the task. Overall, the present study highlights the embodied nature of the mental rotation task of hands by revealing selective effects of motor expertise.

Keywords: mental rotation, motor imagery, embodiment, motor expertise.

\section{Introduction}


Humans have the ability not only to imagine static objects but also to imagine movements and transformations (Piaget and Inhelder 1966), a process referred to as mental imagery. In one of the most used paradigms to access mental imagery, namely the mental rotation task, Shepard and Metzler (1971) asked participants to judge whether two rotated 3D cube figures depicted identical or different objects and observed that response times (RTs) were linearly proportional to the angle of rotation from the original position. This first study suggests that participants executed an internal rotation that is mentally reorienting the rotated object with respect to the other (Shepard and Metzler 1971; Parsons 1994; Jeannerod and Decety 1995). Similar RT patterns are identified in the mental rotation task of twodimensional objects (Cooper 1975), pictures of unfamiliar polygons (Cooper and Podgorny 1976) and asymmetrical alphanumeric characters (Cooper and Shepard 1973) but not to the mental rotation of body parts referred to as the laterality judgment task (Sekiyama, 1982). One distinctive feature of hand laterality judgment task is that the participants must mentally move their corresponding body part until it aligns with the target position (Parsons 1994). Parsons (1994) showed that the time needed to physically match the participant's hand with the stimuli was highly correlated to the RT and that, as for overt movements, participants were faster in the mental rotation of hands toward the mid-sagittal plane (i.e., medial rotation) than in mental rotation of hands away of the mid-sagittal plane (i.e., lateral rotation).

Mental rotation of body parts, as laterality judgment tasks, induces therefore an embodied mental process. This process activates anatomically interconnected brain systems implicated in the integration of sensorimotor information (Bonda, Petrides, Frey, and Evans 1995; Kosslyn, Di Girolamo, Thompson, and Alpert 1998; Parsons et al. 1995) and takes into account kinesthetic aspects or biomechanical constraints (Sekiyama 1982; Parsons 1987; Jeannerod 1994; Shenton, Schwoebel, and Coslett 2004; Sauner, Bestmann, Siebner, and Rothwell 2006; Thayer and Johnson 2006). 
Parsons' findings opened a wide field of investigations on an embodied process referred to as motor imagery (de Lange, Helmich, and Toni 2006; de Lange, Roelofs, and Toni 2008). Motor imagery is defined as the ability to mentally plan and perform an action without overtly performing it in the absence of sensory feedback (Decety 1996a, b). So Parsons, Gabrieli, Phelps, and Gazzaniga (1998) confirmed the embodied nature of motor imagery (MI) in the hand laterality judgment task by showing that mentally discriminating body part handedness depends both on lateralized sensorimotor and somatosensory representations. More recently, the studies of Ionta, Fourkas, Fiorio, and Aglioti (2007) and Ionta and Blanke (2009) found slower RTs for the laterality judgment of right hands compared with left hands when right-handed participants placed their right hand behind their back. This physical kinesthetic aspect or biomechanical constraint induces longer trajectories to mentally reorient the participants' hand until it matches with the stimulus. Indeed, a hand laterality judgment task requires considering the dynamics of the spatial environment, the hand biomechanical limits and the relationship between these two variables that is mainly ensured by MI (Stevens 2005). In such tasks, the participants plan and simulate motion from a first-person perspective without overtly executing it. Instead of relying on sensory feedback, they simulate the perceptual result of the planned movement and make a laterality decision (Annett 1995; Decety 1996; Jeannerod 1994, 2001; Wexler, Kosslyn, and Berthoz 1998).

Despite a body of evidence suggests that the hand laterality judgment task induces the MI strategy, the lack of consensus (Lust, Geuze, Wijers, and Wilson 2006; Steenbergen, van Nimwegen, and Craje 2007) appears to be related to the differences about stimuli view and orientation among the existing studies (Gentilucci, Daprati, and Gangitano 1998; Parsons 1987). Indeed, when the participants performed a laterality judgment task of hand stimuli, an engagement in MI was not shown for hand pictures presented from a back-view perspective in different orientations (Lust et al. 2006; Steenbergen et al. 2007). However, for hand pictures 
presented from different viewpoints, a strong difference was observed between the RTs of medial and lateral rotations confirming the engagement in MI (Ionta et al. 2007). An extensive study of the effect of the hand's view on the mental strategy was carried out by ter Horst et al. (2010) in a hand laterality judgment task. Their findings revealed that, in contrast to stimuli rotated over a single axis and showing no engagement in MI, hand figures rotated over two or three axes depicted positions that were difficult to adopt and consequently induced strong engagement in MI.

As with the number of rotational axes, the type of mental rotation task influences the engagement in motor imagery. In a mental rotation task of hands with a same-different judgment, it would be impossible to engage in MI then visual imagery becomes the primary medium to execute the mental movement. Visual imagery encompasses third-person perspective images that are representations of another person's movements (Ruby and Decety 2001; Sirigu and Duhamel 2001; Steenbergen et al. 2007) and is not an embodied process because it is not subject to biomechanical constraints (ter Horst et al. 2010). In addition, Sirigu and Duhamel (2001) showed that imagining one's own hand movements during the mental rotation task of hands depends on motor processes because it is sensitive to the actual hand posture of the participants. In contrast, imagining a third person's hand movements is not sensitive to the actual hand posture and is mainly based on visual imagery processes (Sirigu and Duhamel 2001).

A successful overt movement requires the transfer of perceptual information into action, and MI is the premium strategy to ensure this transfer (Stevens 2005). Studies on the relationship between imagined and executed one's own body actions provide strong evidence in favor of the activation of the same motor representations during the overt and covert simulations of one's own body actions (Decety 2002; Hommel, Müsseler, Aschersleben, and Prinz 2001; O’Regan and Noë 2001). This close relationship was confirmed using both 
behavioral (Decety, Jeannerod, and Prablanc 1989; Decety and Michel 1989; Parsons et al. 1995) and brain mapping studies (Decety et al. 1994; Gerardin et al. 2000; Jeannerod 2001; Roland, Skinhøj, Lassen, and Larsen 1980; Stephan et al. 1995). Otherwise, the enhancement of sporting performance correlates with an enhancement of imagery quality (Collet, Deschaumes-Molinaro, Delhomme, Dittmar, and Vernet-Maury 1994; Deschaumes-Molinaro, Dittmar, and Vernet-Maury 1991; Roure, Collet, Deschaumes-Molinaro, Delhomme, Dittmar, and Vernet-Maury 1999) and mental rotation performances (Habacha, Molinaro, and Dosseville, in press; Ozel, Larue, and Molinaro 2002). Moreover, the practice of physical activities involving frequent real body rotations improves mental rotation abilities (Moreau, Clerc, Mansy-Dannay, and Guerrin 2012) and "selective effects" of motor expertise in upsidedown orientations of the body (as in gymnasts) were found for human body figures presented in the same orientations as during practice (Steggemann, Engbert, and Weigelt, 2011). This selective effect was only demonstrated in mental body rotation tasks that induced embodied processes (i.e. laterality judgment of human body figures) and thus that allowed the implementation of one's own specific motor expertise. Considering these results, a mental rotation task inducing MI strategies relying on embodied processes (i.e., the hand laterality judgment task) should allow the implementation of one's specific motor expertise.

A physical training of hands' movements is likely combined with mental training at the perceptual level of the same movements, including information of the duration and biomechanical constraints of the hand that executes the movement. In addition, some sports, such as racket sports, require an overuse of the dominant arm. Previous studies have provided evidence of differences between the dominant and non-dominant hand in motor (OlexZarychta and Raczek 2008) and mental (Zartor, Mikheev, and Afanasiev 2010a, b) reactions. Thus, the perception of body part movements is shaped with regard to the body's lateral features and performance on cognitive tasks is dependent on these features (Zartor et al. 
2010a, b). Given that the hand laterality judgment task induces an engagement in MI (Parsons 1987; ter Horst et al. 2010), this task would allow the implementation of one's own motor expertise with hand movements. Accordingly, a dominance of the right or left hand at the physical level would translate into a mental dominance of the same hand at the perceptual level with a faster overt movement time of the right or left hand and consequently into faster RT during the mental simulation of the same movement.

In the present study, we used the hand laterality judgment task with figures of the right and left hands rotated over three axes to evoke the maximum MI engagement (ter Horst et al. 2010). To investigate the effect of motor expertise of the hand movements, we recruited high level table tennis players and compared their performances with the performances of soccer players with same level of expertise. Table tennis is an activity which requires very fast and accurate hand movements over different spatial axes. Thus, we expected that table tennis players will be faster in the hand laterality judgment task than soccer players, whose sport does not require such precise and fast hand movements. Second, the fast and accurate movements in table tennis are executed with one single hand, such that handedness is particularly developed in that sport. Thus, we hypothesized that table tennis players will be faster than soccer players in the judgment of laterality of their dominant (right) hand compared with the non-dominant hand.

\section{Methods}

Participants

Twenty-nine male participants aged between 18 and 28 years $(M=22.8$ years, $\mathrm{SD}=$ 2.8) and right-handed according to the Edinburgh Handedness Inventory Questionnaire (Oldfield 1971) participated in this experiment. . All participants provided their informed 
consent prior to the experiment and reported no former participation in a hand laterality judgment task.

Two groups of participants were formed. The hand movement expert group, aged between 18 and 27 years $(M=23$ years, $\mathrm{SD}=2.8)$, consisted of 14 table tennis players that were recruited from sport clubs. The inclusion criteria included participants that had practiced table tennis for at least six years with a frequency of at least $12 \mathrm{~h}$ per week $\left(M_{\text {training experience }}=\right.$ 9.6 years; range six to 14 years; $S D=2.5$ years). In addition, all table tennis players were practicing at the best national level and represented their country at least once in an international event.

The non-expert group, aged between 18 and 28 years $(M=22.5$ years, SD $=2.8)$, consisted of 15 soccer players that were recruited from sport clubs. As with table tennis players, they had been practicing soccer for at least six years with a frequency of at least $12 \mathrm{~h}$ per week $\left(M_{\text {training experience }}=9.7\right.$ years; range six to 16 years; SD $=2.9$ years $)$. In addition, all soccer players were actually practicing at the best national level and each was a member of the national selection for at least one year. Lastly, they reportedly had no practical experience in table tennis or any other racket sport.

\section{Materials}

The experimental stimuli consisted of figures of the left and right hands. The left hands were mirror images of the right hands. Each figure was individually presented on a black background. The stimuli were displayed on a computer with a $17.3 "(39.60 \mathrm{~cm})$ TFT color screen using specific software developed in our laboratory, which also recorded the reaction times (i.e., from the moment of the appearance of the stimulus until the decision was made) as well as the response accuracy. 
The left and right hand stimuli were rotated over three axes: two longitudinal orientations (back view, palm view), two in-depth rotations $\left(60^{\circ}\right.$ and $\left.300^{\circ}\right)$, and 12 in plane rotations $\left(0^{\circ}, 30^{\circ}, 60^{\circ}, 90^{\circ}, 120^{\circ}, 150^{\circ}, 180^{\circ}, 210^{\circ}, 240^{\circ}, 270^{\circ}, 300^{\circ}\right.$, and $\left.330^{\circ}\right)$, which resulted in 96 stimuli: 48 right-hand stimuli and 48 left-hand stimuli. The rotation over the three axes was executed to encourage maximum engagement in MI. The upright position was defined as the in-plane $0^{\circ}$ orientation with the fingers pointing upward (Fig. 1). The software randomized the display of stimuli, where every figure was represented three times, but not more than two successive times, resulting in 288 test stimuli $(96 \times 3)$. The test stimuli were preceded by a training session of 30 familiarization trials.

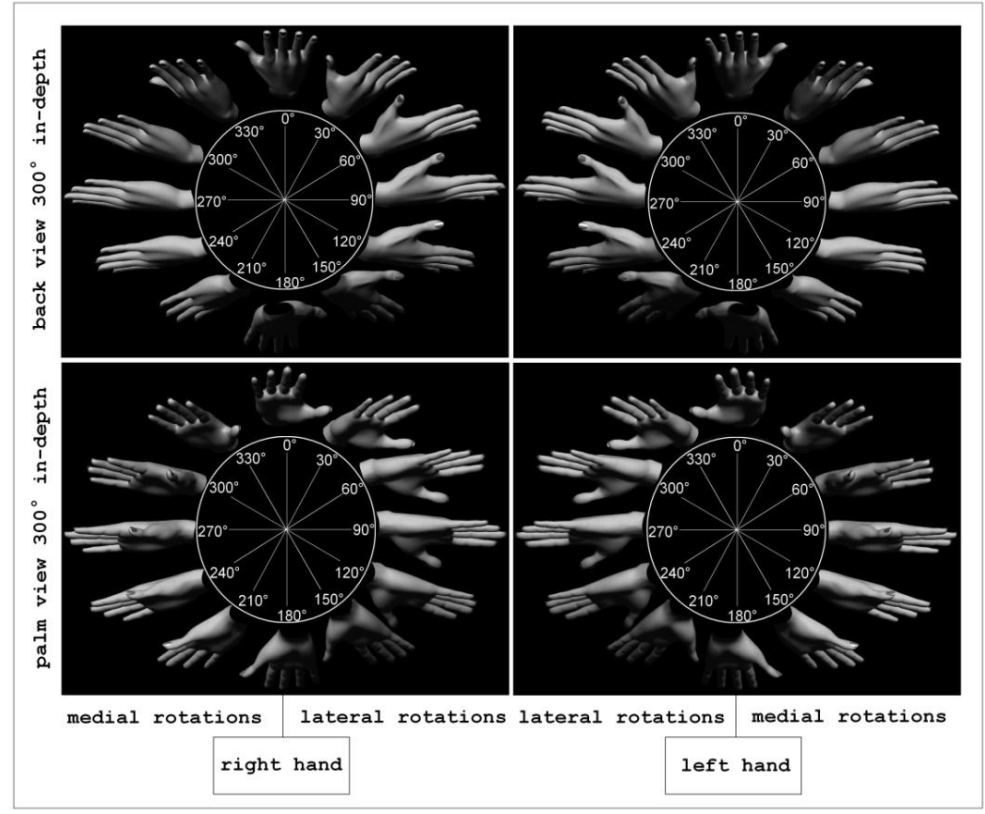

Fig 1. Examples of hand figures with palm and back views at $300^{\circ}$ in-depth and going from $0^{\circ}$ to $330^{\circ}$ in-plane. For right hand figures, the medial rotations are on the left and lateral rotations on the right, and vice versa for the left hand figures.

Experimental procedure 
The participants were individually tested in a darkened room and were seated in front of the computer at a distance of $60 \pm 5 \mathrm{~cm}$ with their left and right index placed on two buttons of the keyboard colored and labeled as the "left hand" and "right hand," respectively. The participants were instructed to judge the laterality of the displayed hand figure as fast and as accurate as possible.

Test trials were interspersed by a blank screen $(1500 \mathrm{~ms})$ followed by a black fixation cross $(500 \mathrm{~ms})$. The stimulus remained visible on the screen for a maximum of $5000 \mathrm{~ms}$, and the next trial began after the response was given. The response accuracy and reaction times were recorded using the same software employed to display the stimuli.

The stimuli were displayed in four blocks of 72 trials with breaks in between each block.

Data analysis

Previous motor imagery studies using behavioral data of the mental rotation tasks of body parts showed that stimulus orientation and stimulus view specifically affect RTs (Cooper and Shepard 1975; Sekiyama 1982; Parsons 1987; Parsons 1994; Bonda et al. 1995; Wohlschläger and Wohlschläger 1998; de Lange et al. 2006). Thus, we focused our analysis only on RTs resulting in correct responses (incorrect responses amounted to $6 \%$ of the trials). In addition, RTs faster than $300 \mathrm{~ms}$ and slower than $3500 \mathrm{~ms}$ were excluded $(0.23 \%)$ similar to previous studies using the hand laterality judgment task (Sekiyama 1987; Parsons 1994; Ionta et al. 2007; Iseki, Hanakawa, Shinozaki, Nankaku, and Fukuyama 2008).

To analyze the direction of rotation (DOR) effect (medial rotations vs. lateral rotations), which enabled measurement of the engagement in MI, we divided the in-plane rotations into medial- and lateral-rotations as previously described in previous studies (Parsons 1987; Parsons 1994; ter Horst et al. 2010). Accordingly, the medial-rotations of the right hand consisted on $210^{\circ}, 240^{\circ}, 270^{\circ}, 300^{\circ}$, and $330^{\circ}$ orientations and the lateral rotations 
of the right hand consisted on $30^{\circ}, 60^{\circ}, 90^{\circ}, 120^{\circ}$, and $150^{\circ}$ orientations, and vice-versa for the left hand rotations.

In the absence of hypotheses about the effect of longitudinal orientations and in-depth rotations, we averaged RTs of the two longitudinal orientations (back view, palm view) and the two in-depth rotations $\left(60^{\circ}\right.$ and $\left.300^{\circ}\right)$ and performed a repeated measure analysis of variance (ANOVA) including DOR (medial rotations, lateral rotations) and laterality (right hand, left hand) as within-subject factors and expertise (hand movement experts, non-experts) as a between-subject factor. Post hoc comparisons were performed using the Bonferroni test, and the alpha level was established at $p=0.05$.

\section{Results}

The amount of incorrect responses did not differ significantly between medial (5.6\%) and lateral rotations $(6.4 \%)$ neither between left hand (5.7\%) and right hand stimuli $(6.3 \%)$. Neither the effect of expertise nor any interaction was significant.

The RTs analysis showed a significant main effect of DOR $(F(1,27)=26.305, p<$ $\left..001, \eta^{2}=.49\right)$. The participants were faster for the medial-rotations $(1658 \mathrm{~ms})$ than for the lateral rotations $(1840 \mathrm{~ms})$. The effect of laterality was also significant $(F(1,27)=13.670, p<$ $\left..001, \eta^{2}=.34\right)$ and faster RTs were observed for the right hand stimuli (1745 ms) with respect to the left hand stimuli $(1753 \mathrm{~ms})$. However, the main effect of expertise did not reach significance $\left(F(1,27)=0.901, p=.351, \eta^{2}=.03\right)$.

The two-way interaction between laterality and expertise was significant $(F(1,27)=$ $\left.25.835, p<.001, \eta^{2}=.49\right)$. Bonferroni post hoc tests revealed that the hand movement experts were faster for right hand stimuli than for left hand stimuli, but this difference was not significant for the non-experts (Fig. 2).

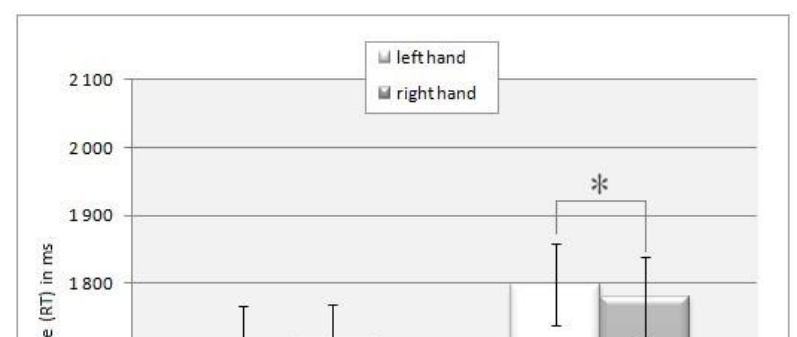


Fig 2. Mean response time (RT) in milliseconds of the hand movement experts and non-experts for the left and right hand stimuli.

The two-way interaction between DOR and expertise was also significant $(F(1,27)=$ $\left.10.867, p=.003, \eta^{2}=.29\right)$. Bonferroni post hoc tests revealed that the non-experts were faster for the medial rotated stimuli compared with the lateral rotated stimuli $(p<.001)$, but no significant difference was observed in the hand movement experts (Fig. 3), but.

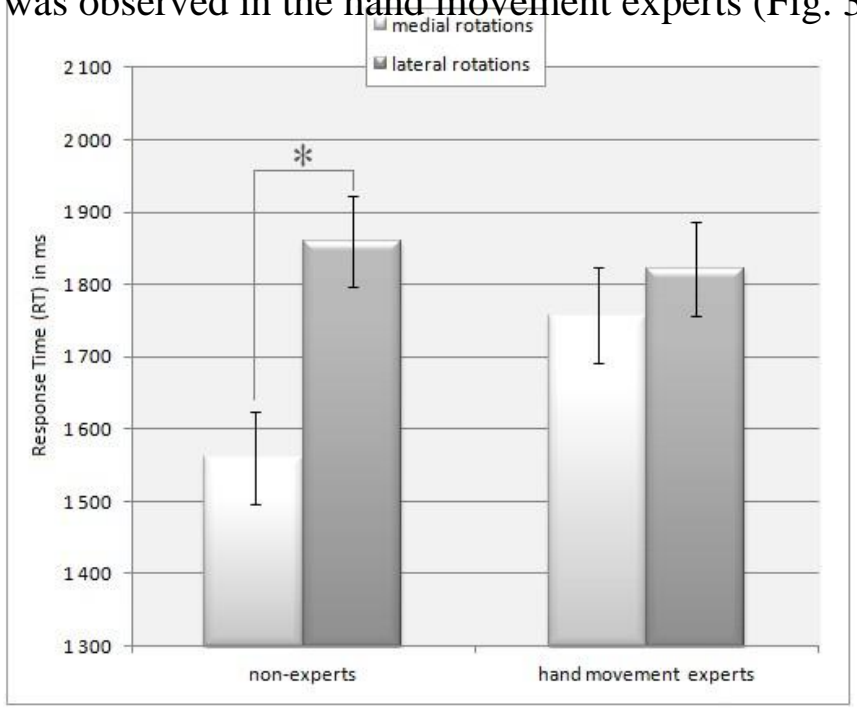

Fig 3. Mean response time (RT) in milliseconds of hand movement experts and non-experts for medial and lateral rotations.

The three-way interaction between DOR, laterality, and expertise reached significance $\left(F(1,27)=9.710, p<.004, \eta^{2}=.27\right)$. Bonferroni post hoc tests showed that the non-expert group was faster in medial rotations than in lateral rotations (Fig. 4) for the right $(p<.001)$ 
and left hand stimuli $(p<.001)$; the hand movement expert group showed the same pattern but only for the left hand stimuli ( $p=.033)$.

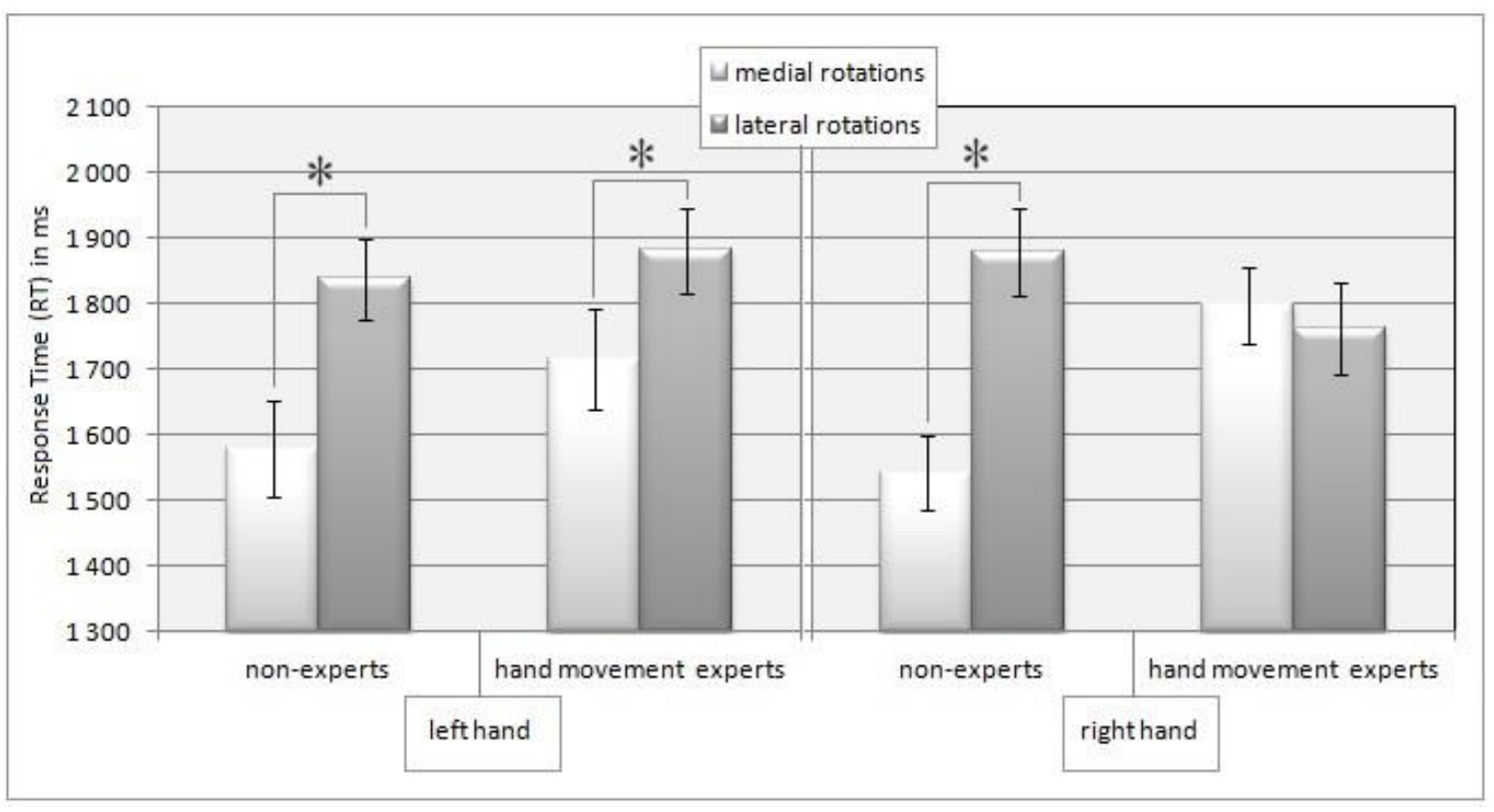

Fig 4. Mean response time (RT) in milliseconds of hand movement experts and non-experts for medial and lateral rotations.

\section{Discussion}

In the present study, we investigated the effect of expertise and laterality in hand movements on a mental rotation task of hands known as the hand laterality judgment task. Performances of the hand movement experts (high level right-handed table tennis players) were compared with those of non-experts (whose sport does not involve fast and accurate hands movements over different spatial axes) in a mental rotation task using left and right hand figures rotated over three axes to encourage maximum engagement in MI.

Analyses showed a significant effect of DOR that was accounted for by smaller RTs for medial compared with lateral rotations. This finding was consistent with previous studies on hand laterality judgment tasks (Parsons 1987; Parsons 1994; ter Horst et al. 2010). Faster RTs for medial rotations compared with lateral rotations classically indicated a significant effect of biomechanical constraints related to the mental path followed to align one's hand's 
mental image with the desired end-state (presented hand posture on the screen). Thus, this effect indicated an engagement in MI, which is subject to biomechanical constraints (Jeannerod 1994; de Lange et al. 2008; ter Horst et al. 2010).

As we previously hypothesized, the engagement in this embodied cognitive processing might promote the effect of laterality and motor expertise in hand movements on the hand laterality judgment task. This assumption was confirmed by analysis of the RTs of the two groups of athletes (hand movement expert group, non-expert group) and according to the two laterality conditions (right hand, left hand). Participants were significantly faster for right hand stimuli compared with left hand stimuli. This finding was consistent with previous results demonstrating a dominant hand preference on the mental body rotation task (Zartor et al. 2010a, b). When engaged in MI during a hand laterality judgment task, the participants succeeded to mentally move their dominant hand image from the current position to the desired end-state faster than their non-dominant hand. This pattern might be due to more familiarity with dominant hand movements due to the well-developed lateralization on righthanders (Gentilucci et al. 1998).

The significant interaction between laterality and expertise allows specifying the reason for this dominant hand advantage. Indeed the hand movement expert group responded faster for right hand stimuli compared with left hand stimuli, but this difference was not significant in the non-expert group. The hand movement experts only used their dominant hand during table tennis practice, and the faster mental rotations were thus achieved only for the dominant hand. Thus, the hand movement expertise was rather a dominant hand movement expertise that was transferred to the mental level.

As we explained previously, the significant main effect of the DOR indicates the engagement in MI. Interestingly, we observed smaller RTs for medial rotations than for lateral rotations only in the non-expert group whereas the hand movement experts performed equally 
for medial and lateral rotations. According to the literature (Jeannerod 1994; de Lange et al. 2008; ter Horst et al. 2010), the logical explanation would be that the hand movement experts did not engage in MI. However, the three-way interaction between DOR, laterality, and expertise offers another suggestion. The effect of the DOR for the non-expert group was significant for the two laterality conditions (right hand stimuli, left hand stimuli); however, the same effect for the hand movement expert group was significant only for left hand stimuli. The table tennis players have the same joint constraints in their right hand as soccer players do, but their specific expertise during training and competitions likely enabled them to practice the lateral rotations by rapid and precise adjustments in limbs, trunk, and shoulders. The adjustment of right hand lateral rotations likely allowed them to inhibit or overcome the biomechanical constraints and was therefore covertly translated during the laterality judgment task. This assumption makes sense because the table tennis players non-dominant hands were still subject to the biomechanical constraints that translated into faster RTs for the medial compared with the lateral rotations. These findings are similar to those of Steggemann et al. (2011) showing that gymnast succeeded to mentally adopt upside-down body postures faster than other athletes did during an embodied perspective taking task, and consequently that the specific expertise from gymnastics practice was implemented during the mental perspective taking task.

Whether RTs for the medial and lateral rotations of the right hand of table tennis players were not significantly different from RTs for medial rotations of the left hand, our argument in favor of a selective effect of table tennis practice would be even stronger if faster RTs for the medial and lateral rotations of the right hand than for medial rotations of the left hand were obtained. It is important to specify that these hand movement experts committed more errors with medial rotation of left hand stimuli (5.6\%) compared to medial (4.6\%) and lateral $(5.4 \%)$ rotations of the right hand stimuli. It is thus possible that other strategies based 
on the visual appearance of the stimuli were used (Jola and Mast, 2005) when the imagined movement of non dominant hand to the position of the stimuli seemed difficult. Locating the position of the thumb relative to the little finger with respect to the longitudinal orientation of the hand figure (palm view, back view) may be a strategy to identify the laterality of the hand. Another explanation, when mentally moving own hand to the position of the stimuli seems hard or impossible as in the case of non dominant hand, relies on the engagement in fast guesses leading to faster RTs.

In addition, soccer players were faster, but not significantly, than table tennis players with the left and right hand stimuli and particularly with medial rotations (see Fig. 2 and Fig. 3). These findings disprove our hypothesis about faster RTs for table tennis players than soccer players but may be due to the greater error rates committed by soccer players $(6.5 \%)$ compared to table tennis players (5.4\%). This non significant difference may be explained by the strategies presented above potentially used by the soccer players.

Several studies have shown that athletes gain their specific expertise not only from practicing but also from observing other athletes performing the same movements, and this visual experience results in a significant improvement in motor learning (Mattar and Gribble 2005; Petrosini et al. 2003). Experts in our study gained a specific motor expertise through physical practice of specific dominant hand movements as well as specific visual expertise through the observation of partners or opponents performing identical movements with their dominant and non-dominant hands. However, the specific visual experience did not seem to have a major effect on the experts' performances on the mental rotation task of hands because they did not succeed in inhibiting the biomechanical constraints of the lateral rotations for their non-dominant hand (observed in partners and opponents). Accordingly, our results revealed that the performances of a hand laterality judgment task were more sensitive to motor expertise compared with visual expertise. 
Taken together, our findings highlight additional factors affecting the performances on a mental rotation task of hands. The present study showed that the classical effect of DOR might collapse because the expertise in the hand movements enabled the participants to perform equally for the medial and lateral rotations only for their dominant hand. This finding suggested that the practice of activities encouraging a dominant hand physical advantage promoted a mental or perceptual dominance of the same hand, which translated into faster RTs and similar RT patterns for medial and lateral rotations of the dominant hand.

To the best of our knowledge, no previous study had examined the effect of hand movement expertise on a laterality judgment task even if it is one of the most commonly known tasks to induce motor processes. Overall, the present study provided additional support for the embodied nature of the hand laterality judgment task and the close relationship between imagined and executed actions. 


\section{References}

Annett J (1995) Motor imagery: Perception and action. Neuropsychologia, 33, 1395-1417.

doi.org/10.1016/0028-3932(95)00072-B

Bonda E, Petrides M, Frey S, Evans A (1995) Neural correlates of mental transformation of the bodyin-space. Proc Natl Acad Sci USA, 92:11180-11184. doi.org/10.1073/pnas.92.24.11180

Collet C, Deschaumes-Molinaro C, Delhomme G, Dittmar A, Vernet-Maury E (1994) Autonomic responses correlate to motor anticipation. Behavioural Brain Research, 63, 71-79. doi.org/10.1016/0166-4328(94)90052-3

Cooper LA (1975) Mental rotation of random two-dimensional shapes. Cognitive Psychology, 7, 20 43. doi:10.1016/0010-0285(75)90003-1

Cooper LA, Podgorny P (1976) Mental transformations and visual comparison processes: Effects of complexity and similarity. Journal of Experimental Psychology: Human Perception and Performance, 2, 503-514. doi:10.1037//0096-1523.2.4.503

Cooper LA, Shepard RN (1973) The time required to prepare for a rotated stimulus. Memory Cognition, 1, 246-250. doi:10.3758/BF03198104

Cooper LA, Shepard RN (1975) Mental transformations in the identification of left and right hands. J Exp Psychol Hum Percept Perform, 104(1):48-56. doi.org/10.1037//0096-1523.1.1.48

Decety J (1996) The neurophysiological basis of motor imagery. Behavioural Brain Research, 77, 4552. doi.org/10.1016/0166-4328(95)00225-1 
Decety J (1996a) Do imagined and executed actions share the same neural substrate? Cogn Brain Res, 3:87-93. doi.org/10.1016/0926-6410(95)00033-X

Decety J (1996b) Neural representations for action. Rev Neurosci, 7:285-297. doi.org/10.1515/REVNEURO.1996.7.4.285

Decety J (2002) Is there such a thing as functional equivalence between imagined, observed, and executed action? In A. N. Meltzoff W. Prinz (Eds.), The imitative mind: Development, evolution, and brain bases (pp. 291-310). Cambridge, England: Cambridge University Press. doi:10.1017/CBO9780511489969.017

Decety J, Jeannerod M, Prablanc C (1989) The timing of mentally represented actions. Behavioural Brain Research, 34, 35-42. doi.org/10.1016/S0166-4328(89)80088-9

Decety J, Michel F (1989) Comparative analysis of actual and mental movement times in two graphic tasks. Brain and Cognition, 11, 87-97. doi.org/10.1016/0278-2626(89)90007-9

Decety J, Perani D, Jeannerod M, Bettinardi V, Tadary B, Woods R et al (1994) Mapping motor representation with positron emission tomography. Nature, 371, 600-602. doi.org/10.1038/371600a0

de Lange FP, Helmich RC, Toni I (2006) Posture influences motor imagery: an fMRI study. Neuroimage, 33:609-617. doi.org/10.1016/j.neuroimage.2006.07.017

de Lange FP, Roelofs K, Toni I (2008) Motor imagery: a window into the mechanisms and alterations of the motor system. Cortex, 44:494-506. doi.org/10.1016/j.cortex.2007.09.002

Deschaumes-Molinaro C, Dittmar A, Vernet-Maury E (1991) Relationship between mental imagery and sporting performance. Behavioural Brain Research, 45, 29-36. doi.org/10.1016/S01664328(05)80177-9

Gentilucci M, Daprati E, Gangitano M (1998) Right-handed and left-handed have different representation of their own hand. Cogn Brain Res, 6(3):185-192. doi.org/10.1016/S09266410(97)00034-7 
Gerardin E, Sirigu A, Lehericy S, Poline JB, Gaymard B, Marsault C et al (2000) Partially overlapping neural networks for real and imagined hand movements. Cerebral Cortex, 10, 1093-1104. doi.org/10.1093/cercor/10.11.1093

Habacha H, Molinaro C, Dosseville F (In Press) Effects of Gender, Imagery Ability and Sports Practice on the Performance of a Mental Rotation Task. American Journal of Psychology.

Hommel B, Müsseler J, Aschersleben G, Prinz W (2001) The theory of event coding: A framework for perception and action planning. Behavioral and Brain Sciences, 24, 849-878. doi:10.1017/S0140525X01000103

Ionta S, Blanke O (2009) Differential influence of hands posture on mental rotation of hands and feet in left and right handers. Exp Brain Res, 195:207-217. doi.org/10.1007/s00221-009-1770-0

Ionta S, Fourkas AD, Fiorio M, Aglioti SM (2007) The influence of hands posture on mental rotation of hands and feet. Exp Brain Res, 183:1-7. doi.org/10.1007/s00221-007-1020-2

Iseki K, Hanakawa T, Shinozaki J, Nankaku M, Fukuyama H (2008) Neural mechanisms involved in mental imagery and observation of gait. Neuroimage, 41:1021-1031. doi.org/10.1016/j.neuroimage.2008.03.010

Jeannerod M (1994) The representing brain: neural correlates of motor intention and imagery. Behav Brain Sci, 17:187-245. doi.org/10.1017/S0140525X00034026

Jeannerod M (2001) Neural simulation of action: A unifying mechanism for motor cognition. NeuroImage, 14, S103-S109. doi.org/10.1006/nimg.2001.0832

Jeannerod M, Decety J (1995) Mental motor imagery: a window into the representational stages of action. Curr Opin Neurobiol, 5:727- 732. doi.org/10.1016/0959-4388(95)80099-9

Kosslyn SM, Di Girolamo GJ, Thompson WL, Alpert NM (1998) Mental rotation of objects versus hands: neural mechanisms revealed by positron emission tomography. Psychophysiology, 35(2):151-161. doi.org/10.1111/1469-8986.3520151

Lust JM, Geuze RH, Wijers AA, Wilson PH (2006) An EEG study of mental rotation-related negativity in children with developmental coordination disorder. Child Care Health Dev, 32:649-663. doi.org/10.1111/j.1365-2214.2006.00683.x 
Mattar AA, Gribble PL (2005) Motor learning by observing. Neuron, 46: 153-160. doi.org/10.1016/j.neuron.2005.02.009

Moreau D, Clerc J, Mansy-Dannay A, Guerrin A (2012) Enhancing spatial ability through sport practice. Journal of Individual Differences, 33: 83-88. doi.org/10.1027/1614-0001/a000075

Oldfield RC (1971) The assessment and analysis of handedness: The Edinburgh inventory.

Neuropsychologia, 1971, 9, 97-113. doi.org/10.1016/0028-3932(71)90067-4

Olex-Zarychta D, Raczek J (2008) The relationship of movement time to hand-foot laterality patterns. Laterality, 13(5), 439-455. doi.org/10.1080/13576500802134623

O’Regan JK, Noë A (2001) A sensorimotor account of vision and visual consciousness. Behavioral and Brain Sciences, 24, 939-973. doi:10.1017/S0140525X01000115

Ozel S, Larue J, Molinaro C (2002) Relation between sport activity and mental rotation: Comparison of three groups of subjects. Perceptual and Motor Skills, 95, 1141-1154. doi:10.2466/pms.2002.95.3f.1141

Parsons LM (1987) Imagined spatial transformation of one's body. Journal of Experimental Psychology: General, 116, 172-191. doi:10.1037/0096-3445.116.2.172

Parsons LM (1994) Temporal and kinematic properties of motor behavior reflected in mentally simulated action. J Exp Psychol Hum Percept Perform, 20:709-730. doi.org/10.1037//00961523.20.4.709

Parsons LM, Fox PT, Downs JH, Glass T, Hirsch TB, Martin CC, Jerabek PA, Lancaster JL (1995) Use of implicit motor imagery for visual shape discrimination as revealed by PET. Nature, 375(6526):54-58. doi.org/10.1038/375054a0

Parsons LM, Gabrieli, JDE, Phelps EA, Gazzaniga MS (1998) Cerebrally lateralized mental representations of hand shape and movement. Journal of Neuroscience, 18, 6539-6548

Petrosini L, Graziano A, Mandolesi L, Neri P, Molinari M, Maria G et al (2003) Watch how to do it! New advances in learning by observation. Brain Res Rev, 42: 252-264. doi.org/10.1016/S0165-0173(03)00176-0

Piaget J, Inhelder B (1966) L'image mentale chez l'enfant. Paris: Presses Universitaires de France. 
Roland PE, Skinhøj E, Lassen NA, Larsen B (1980) Different cortical areas in man in organization of voluntary movements in extrapersonal space. Journal of Neurophysiology, 43, 137-150.

Roure R, Collet C, Deschaumes-Molinaro C, Delhomme G, Dittmar A, Vernet-Maury E (1999) Imagery quality estimated by autonomic response is correlated to sporting performance enhancement. Physiology and Behavior, 66 (1), 63-72. doi.org/10.1016/S00319384(99)00026-8

Ruby P, Decety J (2001) Effect of subjective perspective taking during simulation of action: A PET investigation of agency. Nature Neuroscience, 4, 546-550. doi:10.1038/87510

Sauner D, Bestmann S, Siebner H R, Rothwell JC (2006) No evidence for a substantial involvement of primary motor hand area in handedness judgements: a transcranial magnetic stimulation study. Eur J Neurosci, 23:2215-2224. doi.org/10.1111/j.1460-9568.2006.04731.x

Sekiyama K (1982) Kinesthetic aspects of mental representations in the identification of left and right hands. Percept Psychophys 32:89-95. doi.org/10.3758/BF03204268

Sekiyama K (1987) Mental rotation of kinesthetic hand images and modes of stimulus presentation. The Japanese journal of psychology, 57:342-349. doi.org/10.4992/jjpsy.57.342

Shenton JT, Schwoebel J, Coslett HB (2004) Mental motor imagery and the body schema: evidence for proprioceptive dominance. Neurosci Lett, 370:19-24. doi.org/10.1016/j.neulet.2004.07.053

Shepard RN, Metzler J (1971) Mental rotation of three-dimensional objects. Science, 171, 01-703. doi.org/10.1126/science.171.3972.701

Sirigu A, Duhamel JR (2001) Motor and visual imagery as two complementary but neurally dissociable mental processes. Journal of Cognitive Neuroscience, 13, 910-919. doi.org/10.1162/089892901753165827

Steenbergen B, van Nimwegen M, Craje C (2007) Solving a mental rotation task in congenital hemiparesis: motor imagery versus visual imagery. Neuropsychologia, 45:3324-3328. doi.org/10.1016/j.neuropsychologia.2007.07.002 
Steggemann Y, Engbert K, Weigelt M (2011) Selective effects of motor expertise in mental body rotation tasks: Comparing object-based and perspective transformations. Brain and Cognition, 76, 97 - 105. doi:10.1016/j.bandc.2011.02.013

Stephan KM, Fink GR, Passingham RE, Silbersweig D, Ceballos-Baumann AO, Frith CD et al (1995) Functional anatomy of the mental representation of upper extremity movements in healthy subjects. Journal of Neurophysiology, 73, 373-386.

Stevens JA (2005) Interference effects demonstrate distinct roles for visual and motor imagery during the mental representation of human action. Cognition, 95, 329-350. doi:10.1016/j.cognition.2004.02.008.

ter Horst, A. C., van Lier, R., \& Steenbergen, B. (2010). Mental rotation task of hands: Differential influence number of rotational axes. Experimental Brain Research, 203, 347-354. doi: $10.1007 / \mathrm{s} 00221-010-2235-1$

Thayer ZC, Johnson BW (2006) Cerebral processes during visuomotor imagery of hands. Psychophysiology, 43:401-412. doi: 10.1111/j.1469-8986.2006.00404.x

Wexler M, Kosslyn SM, Berthoz A (1998) Motor processes in mental rotation. Cognition, 68, 77-94. doi.org/10.1016/S0010-0277(98)00032-8

Wohlschläger A, Wohlschläger A (1998) Mental and manual rotation. Journal of Experimental Psychology: Human Perception and Performance, 24, 397-412. doi.org/10.1037//00961523.24.2.397

Zartor AS, Mikheev MM, Afanasiev SV (2010a) Human Body Schema Perception Depends on Lateral Preferences. Doklady Biological Sciences, 1, 430, 14-16. doi:10.1134/S0012496610010059

Zartor AS, Mikheev MM, Afanasiev SV (2010b) Lateral Peculiarities of the Process of Mental Rotation of the Human Body Scheme. Journal of Evolutionary Biochemistry and Physiology, 46(3), 292-294. doi:10.1134/S0022093010030117 